\title{
Study on the Method for Collecting Vibration Signals from Mill Shell Based on Measuring the Fill Level of Ball Mill
}

\author{
Peng Huang, Minping Jia, and Binglin Zhong \\ School of Mechanical Engineering, Southeast University, Nanjing 211189, China \\ Correspondence should be addressed to Peng Huang; feihonghp@163.com
}

Received 17 April 2014; Revised 26 June 2014; Accepted 30 June 2014; Published 15 July 2014

Academic Editor: Qingsong Xu

Copyright (C) 2014 Peng Huang et al. This is an open access article distributed under the Creative Commons Attribution License, which permits unrestricted use, distribution, and reproduction in any medium, provided the original work is properly cited.

\begin{abstract}
At present the method for measuring the fill level which used the vibration signal of mill shell shows its advantage compared with other methods. However, this method is developed late, and the technique for collecting the vibration signal from mill shell is immature. In this paper, a novel method for collecting the vibration data from mill shell is proposed. Firstly, the layout scheme of vibration sensors on mill shell is given by analyzing the axial and circumferential movement of coal powder in roller. And a special data acquisition system is developed, which can acquire vibration data from different axial and circumferential positions on mill shell. Then the sampling frequency is obtained based on impact model and hierarchical model of steel balls. At the same time, the impact region on mill shell caused by steel balls is considered as the collecting region of vibration signals. Experimental result shows that vibration signals collected by the method proposed in this paper present a high sensitivity to the changes on fill level compared with vibration data of mill bearing, which provides a reliable basis for accurate measurement of the fill level.
\end{abstract}

\section{Introduction}

It is well known that the ball mill pulverizing system has advantages of good adaptability for mineral aggregate of different types, and it has been widely employed in power plant, cement industry, chemical industry, metallurgy, and many other fields. However, this system needs high energy intensive. For example, in the power plant, it makes up about 20 percent of all electricity consumption of power plant $[1,2]$. So making the mill operation safely and having high efficiency are important goals for enterprises. Because the ball mill system is of nonlinearity, long time delay, and timevarying, the fill level of coal powder cannot be measured accurately, which leads the mill to be operated usually under very uneconomical condition to prevent the coal blockage, and the automatic control system is also hard to accomplish steady operation of the mill. Thus the exact measurement of fill level is a key and basic factor for realizing automatic, reliable, and efficient operation of the mill system.

Amongst current techniques of measuring the fill level, the vibration method that can measure the fill level through extracting the power, energy, and vibrated root mean square (RMS) from vibration signal of the mill bearing housing has been applied widely [3-5]. However, there are many reasons and vibration sources to cause the vibration of bearing housings. In addition to the impact of steel balls in roller, there are still some other vibration sources, such as transmission system vibration, foundation vibration, vibration caused by the rotational asymmetry, and installation error. These vibration sources will affect the time and frequency domain characteristics of vibration signals of bearing housings. Furthermore, vibration transmission path also has a certain impact for vibration signals of bearing housings. So vibration signals of the bearing housings cannot accurately reflect the collision condition of steel balls in the mill and the fill level information.

Because the vibration of mill shell is caused directly by the impact of steel balls in roller, this signal can reflect directly and exactly the fill level information compared with vibration data of bearing housings. However, due to the rotating of mill shell, collecting the vibration signal from mill shell is difficult, and the study on measuring fill level which used this signal is relatively little. Among these, the work of Gugel et al. $[6,7]$ was noteworthy. In their work, two vibration sensors, 180 degrees apart (shown in Figure 1), were used to collect signal information from the mill shell so that 

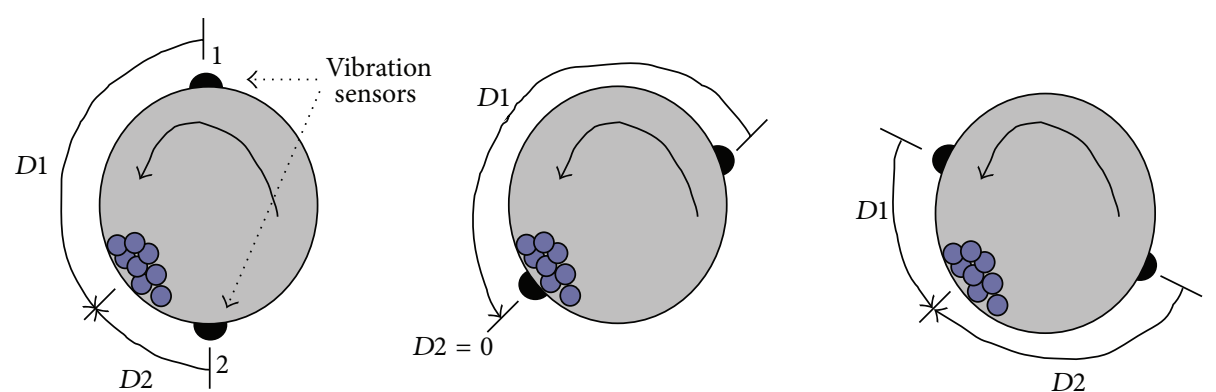

Figure 1: Three different sensor alignment examples for two-sensor based shell system [6]. Note: $D 1=$ distance from sensor 1 to point of impact. $D 2=$ distance from sensor 2 to point of impact. $D 1+D 2=$ mill circumference $/ 2$.

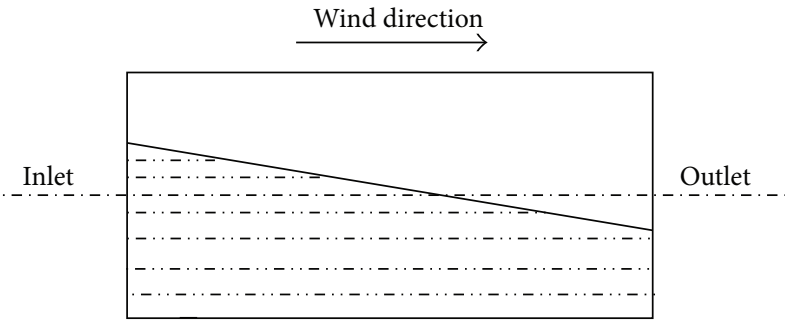

(a) The longitudinal section of mill

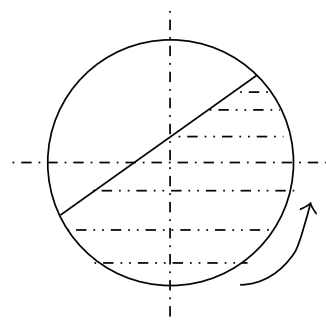

(b) The cross section of mill

FIGURE 2: The schematic diagram of coal powder distribution in roller [9].

instantaneous readings can be averaged together, and the averaged data was fed into a dynamic neural network and a fill level measurement from 0 to 100 percent was output. But this technique has just started, and the data acquisition method is not mature. In the process of data collection, the layout of vibration sensors on the mill shell, the determination of sampling frequency, and choosing the collection region all need to be studied in depth. And these problems will be discussed and resolved in this paper.

\section{Layout of Vibration Sensors}

Because the working situation in mill roller cannot be observed directly, the distribution of coal powder cannot be accurately obtained. At present it is generally thought that the inside of drum is divided by a belt of demarcation [8]. Above the belt of demarcation, there is a flowing space of coal powder airflow. Under the belt of demarcation, there is a motion space of mixed materials, and the mixed materials are composed of coal cinder, coal powder, and steel balls. The motion of mixed materials can be described by the axial and circumferential movements. For the axial motion, the amount of coal at the inlet of mill will be increased firstly along with the increase of the coal inputting, and then the amount of coal at the outlet of mill begins to rise when coal is sent to the outlet of the mill by airflow. From the perspective of longitudinal section of mill, the dividing line is declining from the inlet to the outlet, as shown in Figure 2(a) [9]. The circumferential motion of mixed materials is shown in Figure 2(b) because of the influence of rotation of mill.
It is clearly shown in Figure 2(a) that the distribution of coal powder is nonuniform in roller. So information from only a vibration sensor installed on the mill shell cannot describe the amount of coal completely. In this study, according to the distribution characteristic of coal powder, four acceleration sensors are installed at different positions that locate at the same axis on the mill shell, as shown in Figure 3 (sensors 1, 2, 3, and 4). In the conventional vibration method for measuring fill level, two acceleration sensors (sensors 5 and 6, as shown in Figure 3) are installed at forward and back bearing housing, separately.

\section{Data Acquisition System of the Shell Signal}

Sensors that are installed on the mill shell will rotate together with the rotation of mill, which is not the same with the traditional vibration method that sensors can be directly connected with data acquisition computer by cable. So a special data acquisition system was developed in this study. This system is also installed on the mill shell, which was connected with sensors by sensor cables, and can transfer the signals to computer by wireless way. This system consists of host computer and slave computer two-level system. The function of the slave system is data acquisition and transferring the data to computer. The function of host system is receiving, saving, displaying, and analyzing signals. Figure 4 shows the overall structure of this data acquisition system.

Because sensors mounted on the mill shell will rotate together with the mill and the vibration strength differentiates significantly at different circumferential positions on mill 


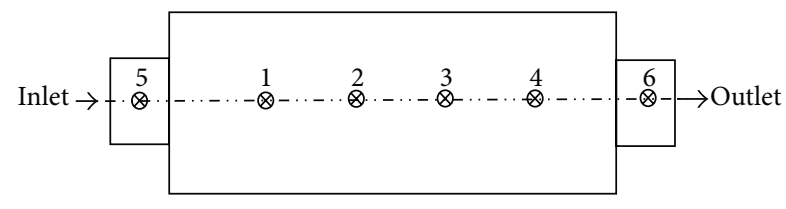

FIGURE 3: Schematic diagram of the fixed position of acceleration sensors.

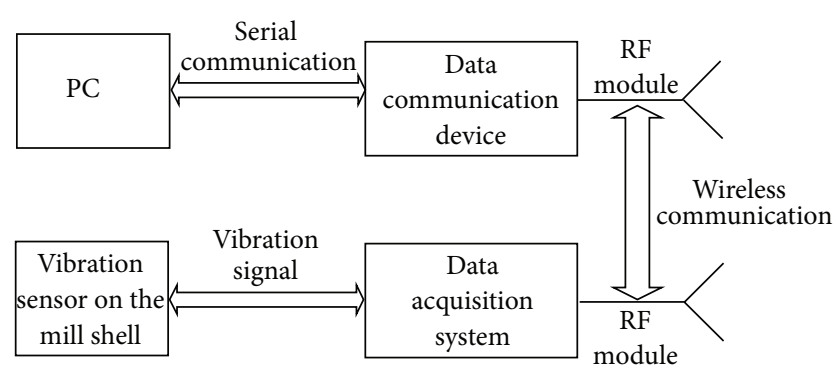

FIGURE 4: Structure of data acquisition system.

shell, sensors need to be controlled to collect signals at the designated circumferential position. This difficult problem is solved by photoelectric switch in this research, and Figure 5 shows its working principle.

In Figure 5, a trigger device of photoelectric switch is placed below the mill. When the photoelectric switch passes through this device, a switch signal will be generated, and this trigger position is considered as the initial phase of sensors. And the collecting position on mill shell can be confirmed by the delay time transferred from host system. Figure 6 shows a real photo of the slave system.

\section{Confirming the Sampling Frequency of the Vibration Signal}

In the process of signal acquisition, if the sampling frequency is set too low, the frequency spectrum of signal will produce overlapping phenomenon, which leads to the distortion of signal. So the appropriate sampling frequency is the key to guarantee the accuracy of data acquisition. According to the Nyquist sampling theory, when sampling frequency $\left(f_{s}\right)$ is 2 times higher than the highest frequency $\left(f_{\max }\right)$ of signal, the sampled signal can accurately reflect the information of original signal [10]. However for the impact vibration signal, the highest frequency in the spectrum may be infinite, and the determination of sampling frequency is difficult.

If the high frequency part of signal can be cut, the highest frequency of signal is considered as limited value. At the same time, the loss of signal information is little, and the sampling frequency is not too high in accordance with the sampling theory [11]. For the vibration signal of mill shell, the main scope of frequency response caused by the impact of steel ball needs to be obtained, and the maximum frequency of this scope is considered as the highest frequency of signal to obtain the sampling frequency. In this research, this frequency band is gained by the theoretical derivation,

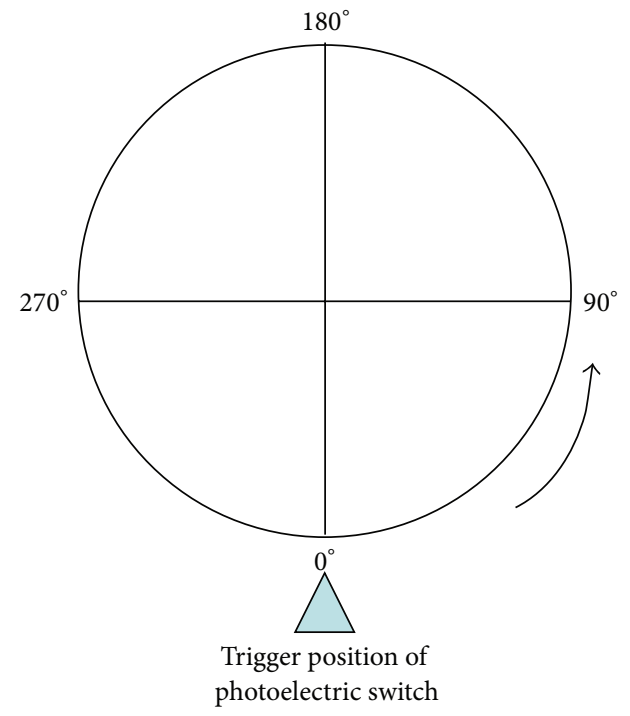

FIgURE 5: The work functional diagram of photoelectric switch.

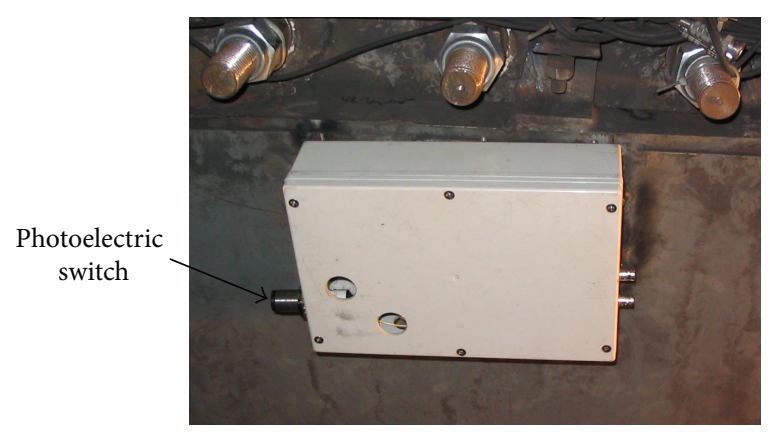

FIGURE 6: Installation image of the slave system mounted on the mill shell.

which is combined with the actual vibration signal of mill shell to determine the sampling frequency.

4.1. Model of Steel Ball Impact. In the operational process of mill, the mill shell is impacted continuously by steel balls, and the impact force can be seen as a series of instantaneous force [12]. So in this study, the situation that the single steel ball impacts the mill shell needs to be analyzed simply, and the characteristics of frequency spectrum for the shell vibration will be obtained. Figure 7 shows the radial vibration of shell caused by impact of a single steel ball.

The action spot on the shell caused by impact of a single ball is $\phi=\phi_{0}$, and the instantaneous impact force $f(\phi, t)$ at time $\tau$ can be described by

$$
f(\phi, t)=f(\tau) \delta\left(\phi-\phi_{0}\right) \delta(t-\tau),
$$

where $f(\tau)$ is the impact force of steel ball, $\delta\left(\phi-\phi_{0}\right)$ is unit impulse function whose variable is angle, and $\delta(t-\tau)$ is unit impulse function whose variable is time. $f(\tau)$ can be obtained by the theorem of impulse:

$$
f(\tau)=\frac{m \Delta v}{\Delta \tau}
$$




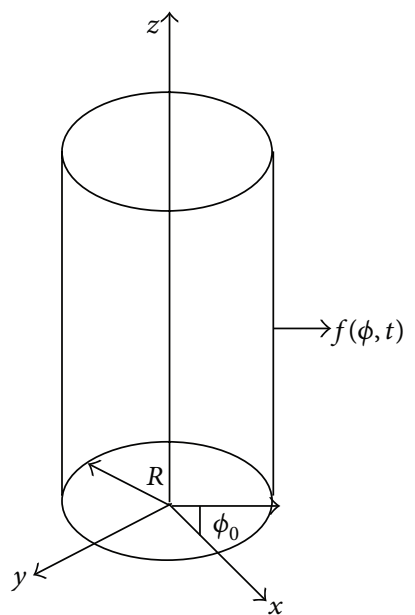

FIgURE 7: The model of shell vibration caused by a single steel ball.

where $m$ is the mass of steel ball and $\Delta v$ is velocity variation of steel ball when this ball runs $\Delta \tau$ time.

According to the vibration theory, the radial displacement of the shell $u$ meets the Poisson equation [13], which is expressed by

$$
\frac{\partial^{2} u}{\partial t^{2}}-c^{2} \Delta u=f(\phi, t)
$$

where $c$ is the propagation velocity of vibration in the mill shell, which can be calculated as follows:

$$
c=\sqrt{\frac{k}{\rho}}=\sqrt{\frac{2.0 \times 10^{11}}{7.8 \times 10^{3}}}=5.06 \times 10^{3} \mathrm{~m} / \mathrm{s},
$$

where $\rho$ is the density of mill shell $\left(7.8 \times 10^{3} \mathrm{~kg} / \mathrm{m}^{3}\right)$ and $k$ is Young's modulus.

In the cylindrical coordinate system (see Figure 7), the following equation is obtained by (1) combined with (3):

$$
\frac{\partial^{2} u}{\partial t^{2}}-\frac{c^{2}}{R^{2}} \frac{\partial^{2} u}{\partial \phi^{2}}=f(\tau) \delta\left(\phi-\phi_{0}\right) \delta(t-\tau) .
$$

At both sides of (5) for integral of $t$, and combined with (2), can be determined by

$$
u_{t} \mid \tau_{+0}=\frac{m \Delta v}{\Delta \tau \delta\left(\phi-\phi_{0}\right)} .
$$

Taking into account the boundary condition, the whole problem can be represented as

$$
\begin{gathered}
\frac{\partial^{2} u}{\partial t^{2}}-\frac{c^{2}}{R^{2}} \frac{\partial^{2} u}{\partial \phi^{2}}=0, \\
u_{t} \mid \tau_{+0}=\frac{m \Delta v}{\Delta \tau \delta\left(\phi-\phi_{0}\right)}, \\
\left.u\right|_{\phi=0}=\left.u\right|_{\phi=2 \pi} .
\end{gathered}
$$

The radial displacement of the shell is obtained by segregation variable method as follows:

$$
u(\phi, t)=\sum_{n} \frac{m R \Delta v}{c n \pi \Delta \tau \sin (c n \tau / R)} \cos \left(\frac{c n t}{R}\right) \cos (n \phi),
$$

where $n$ is mode of vibration and $R$ is the distance between the steel ball and the axis of mill shell.

The vibration velocity of mill shell is gained by the derivation of (8):

$$
\begin{aligned}
v(\phi, t) & =\frac{\partial u(\phi, t)}{\partial t} \\
& =-\sum_{n} \frac{m \Delta v}{\pi \Delta \tau \sin (c n \tau / R)} \sin \left(\frac{c n t}{R}\right) \cos (n \phi) .
\end{aligned}
$$

The vibration acceleration of mill shell can be denoted as

$$
\begin{aligned}
a(\phi, t) & =\frac{\partial v(\phi, t)}{\partial t} \\
& =-\sum_{n} \frac{m \Delta v c n}{\pi \Delta \tau R \sin (c n \tau / R)} \cos \left(\frac{c n t}{R}\right) \cos (n \phi) .
\end{aligned}
$$

It can be seen from (10) that the vibration frequency of mill shell caused by impact of single steel ball in the frequency spectrum is distributed. And its value connects with the propagation velocity of vibration in the mill shell $c$, the distance between the steel ball and the axis of mill shell $R$, and mode of vibration $n$. The discrete frequency caused by the impact of steel ball can be represented as

$$
f=\frac{\omega_{1}}{2 \pi}=\frac{c n}{2 \pi R},
$$

where $\omega_{1}$ is the angular frequency of impact vibration, which can be obtained by (9) and (10).

Practical experience shows that the first 15 modes of vibration can express the vibration condition completely for the structure of high freedom degree [14]. So in (11), $n$ can take the first 15 modes of vibration. However, the different steel balls may move at different steel ball layers in roller, and $R$ value will be verified with different layers. The hierarchical model of steel balls needs to be built to calculate the $f$ value.

4.2. Hierarchical Model of Steel Balls. In roller, steel balls are layered ideally at any cross section, and Figure 8 shows the layered condition of steel balls. In this study, the motion conditions of other layer balls are considered similarly with those of the first layer. The ball at the first layer moves the circular motion along with the rotation of mill firstly and then moves the parabolic motion when this ball is promoted to a certain height. In Figure 9, the radius of circular motion for each layer is denoted by $R_{i}$. In the experiment, the radius of mill shell is $1.75 \mathrm{~m}$, and the diameter of steel ball $d$ is $0.05 \mathrm{~m}$. Therefore, the radii of circular motion from the first layer to $i$ th layer are $1.75 \mathrm{~m}, 1.70 \mathrm{~m}, 1.65 \mathrm{~m}, \ldots,\left(1.80-i^{*} d\right) \mathrm{m}$, respectively. 


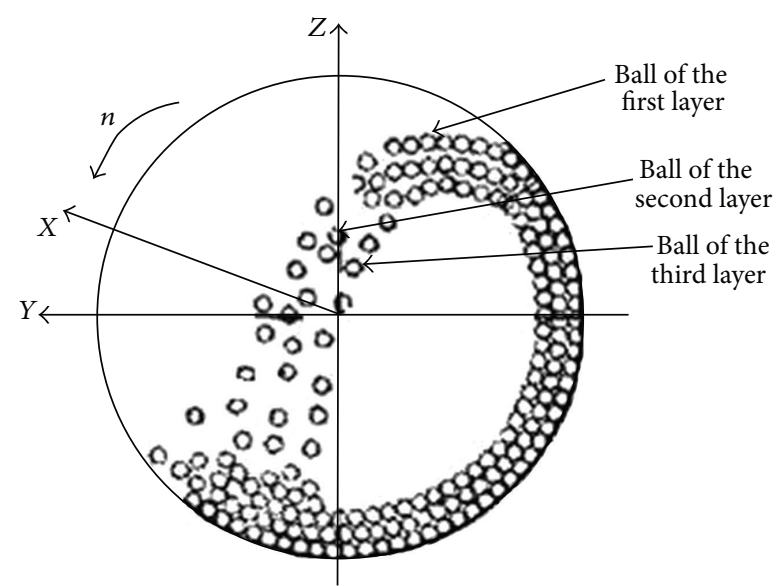

FIGURE 8: Schematic diagram of layered condition of steel balls.

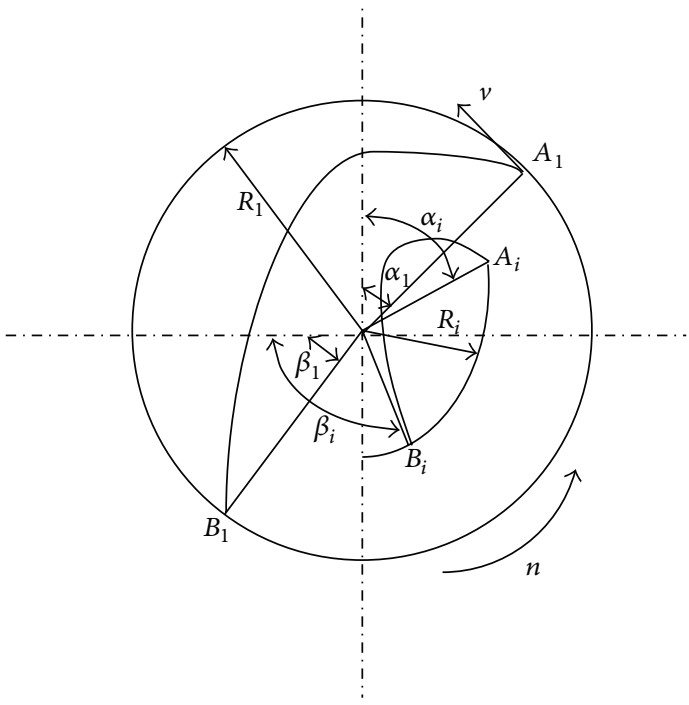

FIGURE 9: Schematic diagram of motion trajectory of each layer balls in roller.

For steel ball at the first layer, the following equations can be obtained by its motion trajectory of circular and parabolic motions:

$$
\begin{gathered}
\beta_{1}=3 \alpha_{1}-\frac{\pi}{2}, \\
a_{1}=\arccos \left(\frac{\left(\pi n_{1}\right)^{2} R_{1}}{900 g}\right),
\end{gathered}
$$

where $n_{1}$ is the rotation speed of mill and $g$ is the acceleration of gravity, $9.8 \mathrm{~m} / \mathrm{s}^{2}$.
Because the motion trajectories of other layers balls are similar to those of the first layer, the following equations can be gained:

$$
\begin{gathered}
\beta_{i}=3 \alpha_{i}-\frac{\pi}{2}, \\
a_{i}=\arccos \left(\frac{\left(\pi n_{1}\right)^{2} R_{i}}{900 g}\right) .
\end{gathered}
$$

The runtime of parabolic motion for the ball of $i$ th layer can be calculated as follows:

$$
t_{s i}=\frac{60 \sin 2 a_{i}}{\pi n_{1}} .
$$

The time interval that two adjacent balls are thrown from the starting point of parabolic motion $A_{i}$ (in Figure 9) at the $i$ th layer can be represented as

$$
t_{p i}=\frac{d}{\omega_{2} R_{i}},
$$

where $\omega_{2}$ is the angular velocity of mill. And at the $i$ th layer the number of balls on the parabolic segment is calculated from

$$
I_{a i}=\left[\frac{t_{s i}}{t_{p i}}\right],
$$

where [] means to round numbers. And at the $i$ th layer the number of balls on the circular segment is calculated from

$$
I_{q i}=\left[\frac{A_{L i}}{d}\right]
$$

where $A_{L i}$ is the arc length of the circular motion, which is obtained by

$$
A_{L i}=\frac{\left(360-4 \alpha_{i}\right) \pi R_{i}}{180}
$$

So the number of balls at the $i$ th layer is expressed by

$$
I_{i}=I_{a i}+I_{q i}
$$

The number of balls layers $M$ can be solved by the following equation:

$$
\sum_{i=1}^{N} I_{i} \leq \operatorname{int}\left[\frac{M_{\mathrm{Q}}}{(m(L / d))}\right] \leq \sum_{i=1}^{N+1} I_{i}
$$

where $M_{Q}$ is the total mass of steel balls, $m$ is the mass of single steel ball, and $L$ is the lateral length of mill shell and is equal to $6 \mathrm{~m}$.

In the experiment, the total mass of steel balls is 38 tones, and steel balls are distributed evenly along the 120 axis sections of mill shell. Because the motion conditions of balls for every section are almost identical, the hierarchical condition of balls needs to be analyzed for any section simply [15]. Table 1 shows the hierarchical condition of balls at a certain axis section of mill shell. 
TABLE 1: The hierarchical condition of steel balls.

\begin{tabular}{lcccc}
\hline $\begin{array}{l}\text { The serial } \\
\text { number of } \\
\text { balls layer }\end{array}$ & $t_{s i}\left(10^{-2} \mathrm{~s}\right)$ & $I_{a i}$ & $I_{q i}$ & $I_{i}$ \\
\hline 1 & 1.55 & 68 & 90 & 158 \\
2 & 1.60 & 65 & 85 & 150 \\
3 & 1.65 & 62 & 80 & 142 \\
4 & 1.75 & 59 & 75 & 134 \\
\hline
\end{tabular}

The impact condition of mill shell caused by steel balls of different layers can be simplified as the impact condition that steel balls impact the shells of different radii. According to (11), the scope of vibration frequency of mill shell caused by impact of balls at $i$ th layer is $c / 2 \pi R_{i} \sim 15 c / 2 \pi R_{i}$ when $n$ takes the first 15 modes of vibration. Table 2 shows the impact discrete frequency of each layer ball.

In Table 2, the impact vibration frequency of mill shell caused by a single ball at different layers is distributed in the scope $460 \sim 7560 \mathrm{~Hz}$. In practical work process of mill, mill shell is impacted by many layers balls, and every layer has a great quantity of balls. So the impact vibration frequency of mill shell can be regarded as continuous, and its scope is 460 7560 Hz.

4.3. Confirming the Sampling Frequency. According to the above information, the theoretical highest frequency $\left(f_{\max }\right)$ of vibration signal is $7560 \mathrm{~Hz}$, and the sampling frequency $\left(f_{s}\right)$ should be 2 times higher than $f_{\max }$ based on Nyquist sampling theory. However in practical engineering application, the sampling frequency $\left(f_{s}\right)$ should be $5 \sim 10$ times of $f_{\max }$ to describe the signal accurately [16]. In order to choose the appropriate sampling frequency, in experiment the sampling frequencies $\left(f_{s}\right)$ were set at $20 \mathrm{KHz}, 40 \mathrm{KHz}, 50 \mathrm{KHz}$, and $60 \mathrm{KHz}$ to collect vibration signals, respectively. And the sampling point was set at 4096 points. In experiment, the steel balls load was 38 tones, and coal feed amount was $55 \mathrm{t} / \mathrm{h}$. Figure 10 shows the frequency spectrums of vibration signals at different sampling frequency conditions.

It can be seen from Figure 10(a) that the amplitude is still considerable at the biggest frequency $(10000 \mathrm{~Hz})$ when sampling frequency $(20 \mathrm{KHz})$ is twice as much as the theoretical highest frequency $\left(f_{\max }=7560 \mathrm{~Hz}\right)$. This shows that this sampling frequency $(20 \mathrm{KHz})$ cannot describe the original vibration information accurately. In Figures 10(b), 10(c), and $10(d)$, the amplitude of high frequency part is little when the sampling frequency exceeds $f_{\max } 5$ times, and the signal can describe the original impact information of steel balls entirely. When the sampling demand is met, the sampling frequency should be set at a low value to enhance frequency resolution. Therefore in this study, the sampling frequency is set at $40 \mathrm{KHz}$.

\section{Confirming the Region of Signal Acquisition}

As sensors rotate with the rotation of mill, the collecting region of sensors on mill shell needs to be determined. Due to
TABLE 2: Vibration frequency of mill shell caused by impact of each layer balls.

\begin{tabular}{lccc}
\hline $\begin{array}{l}\text { The serial } \\
\text { number of } \\
\text { balls layer }\end{array}$ & $\begin{array}{c}\text { Frequency at } \\
\text { first mode of } \\
\text { vibration (Hz) }\end{array}$ & $\begin{array}{c}\text { Frequency at } \\
\text { 15th mode of } \\
\text { vibration (Hz) }\end{array}$ & $\begin{array}{c}\text { Scope of } \\
\text { vibration } \\
\text { frequency of } \\
\text { mill shell (Hz) }\end{array}$ \\
\hline 1 & 460 & 6900 & $460 \sim 6900$ \\
2 & 474 & 7110 & $474 \sim 7110$ \\
3 & 488 & 7320 & $488 \sim 7320$ \\
4 & 504 & 7560 & $504 \sim 7560$ \\
\hline
\end{tabular}

a close relationship between the vibration of mill shell and fill level, in this research the impact region of the first layer steel balls on mill shell is chosen as the region of data acquisition. In the author's previous study, the charge motion of mill has been simulated by DEM (Discrete Element Method) [17, 18]. And the impact region of the first layer steel balls is shown in Figure 11. In order to reduce the acquisition group and time of vibration signals, the region of data acquisition is in the range of $310^{\circ} \sim 340^{\circ}$ on mill shell, as shown in Figure 11. In other words, only when the sensors rotate in this region will it be in a work state.

According to sampling frequency $f_{s}$ and sampling point $N$, the time span of collecting a set of data can be obtained by

$$
t=\frac{N}{f_{s}} .
$$

When a set of data is collected, the angular of mill shell running is calculated by

$$
\theta=\frac{6 n_{1} N}{f_{s}} .
$$

According to (22), $f_{s}, N$, and $n_{1}, \theta$ value is $10.80^{\circ}$. In other words, this vibration data contains vibration information of about 10 degrees arc length of mill shell. In order to obtain the vibration information of collected region (between $310^{\circ}$ and $340^{\circ}$ on mill shell), sensors need to work at angular positions $310^{\circ}, 320^{\circ}$, and $330^{\circ}$ on mill shell, respectively.

\section{Results and Discussion}

6.1. Calculating the Sensitivity Index of Reflecting Fill Level Change. The vibration signals of mill shell can reflect information of fill level directly and accurately compared with vibration data of bearing housings, which is demonstrated by the vibrated mechanism of mill shell and bearing housing that is introduced in the above content. However this conclusion is only the result of theoretical analysis, and it needs to be verified by analysis of actual data. In this research, the superior signal for measuring fill level is confirmed by comparing the sensitivity that vibration signals of mill shell and bearing housing reflect the change of fill level. The sensitivity index of reflecting fill level change is calculated by the RMS of these two kinds of vibration signals.

During the working condition of ball mill, the amount of fill level can be controlled by the coal feeder. When the coal 


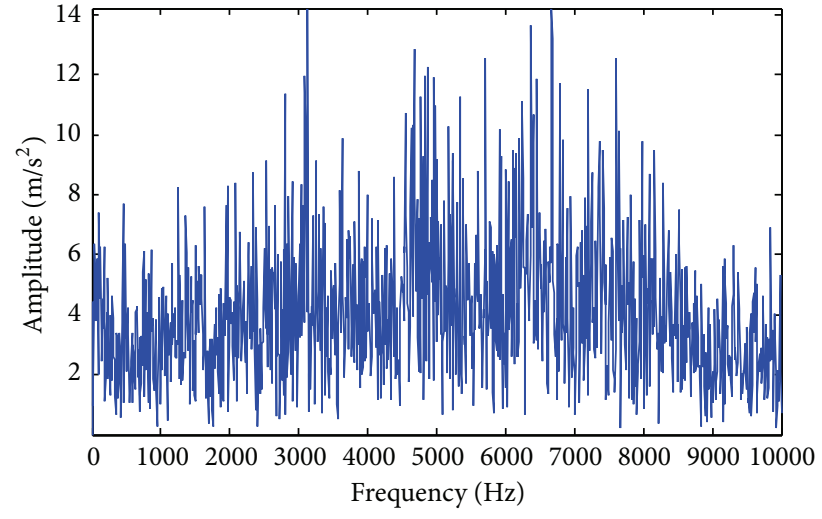

(a) $f_{s}=20000 \mathrm{~Hz}$

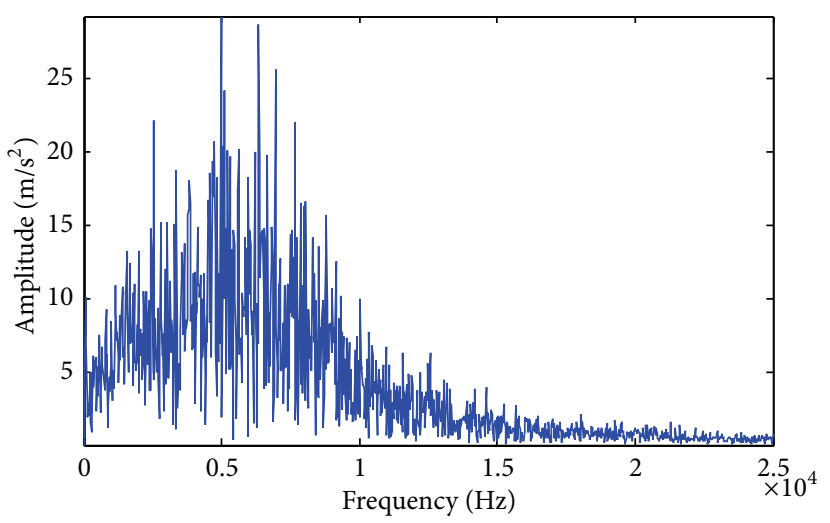

(c) $f_{s}=50000 \mathrm{~Hz}$

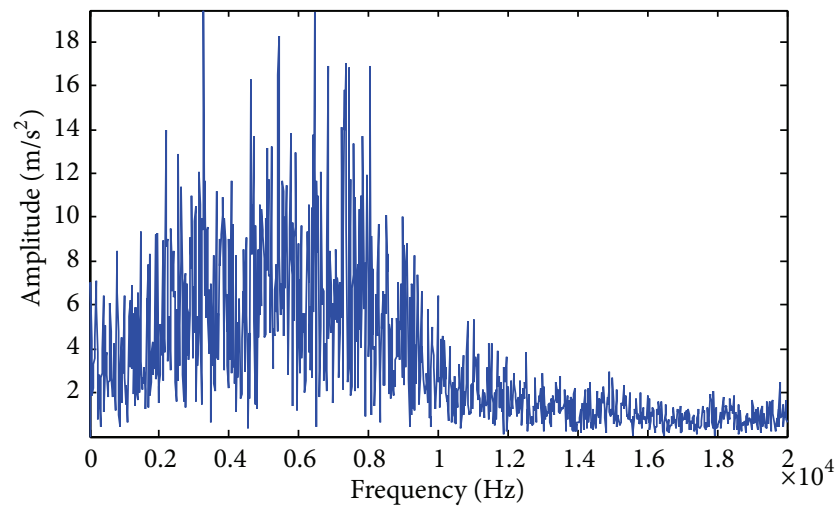

(b) $f_{s}=40000 \mathrm{~Hz}$

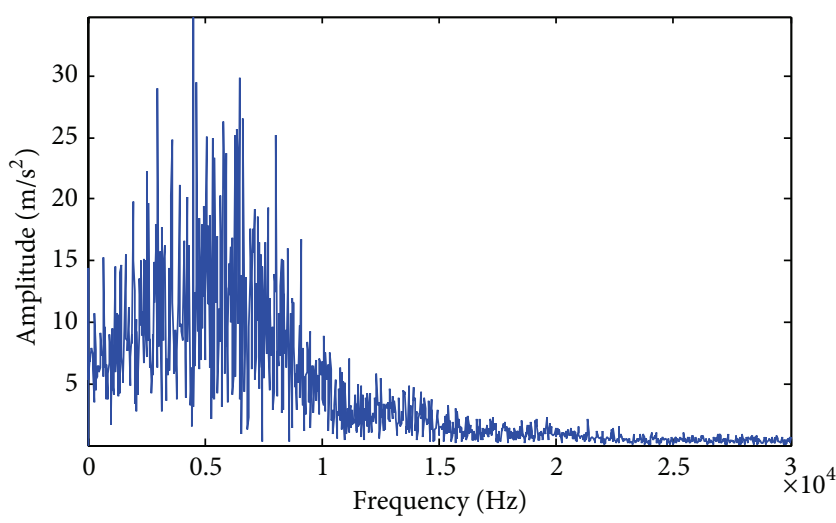

(d) $f_{s}=60000 \mathrm{~Hz}$

FIGURE 10: Frequency spectrums of vibration signals at four types of sampling frequencies.

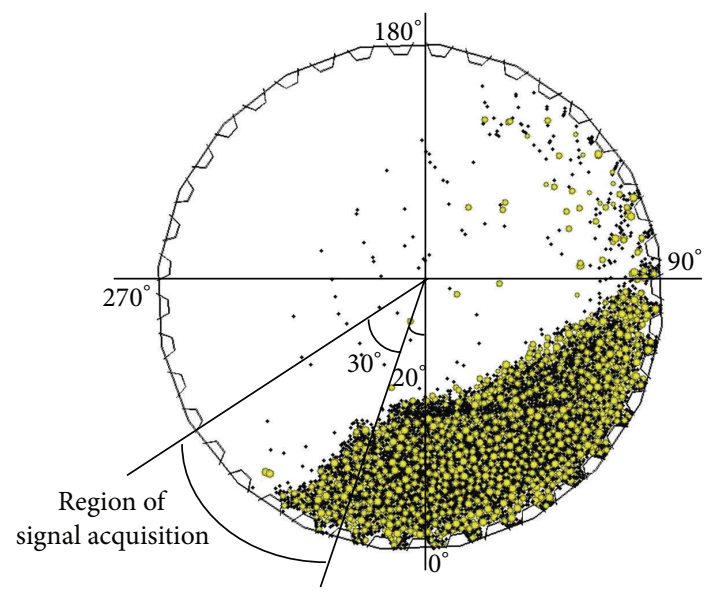

FIgURE 11: The region of data acquisition on mill shell.

feeder is set higher, the fill level is higher, and vice versa. So the different coal feed amount conditions can denote different fill level conditions. In experiment, the vibration signals were collected under eight stable coal feed amount conditions, that is, $0 \mathrm{t} / \mathrm{h}, 20 \mathrm{t} / \mathrm{h}, 30 \mathrm{t} / \mathrm{h}, 35 \mathrm{t} / \mathrm{h}, 40 \mathrm{t} / \mathrm{h}, 45 \mathrm{t} / \mathrm{h}, 50 \mathrm{t} / \mathrm{h}$, and $55 \mathrm{t} / \mathrm{h}$. The sampling frequency of bearing housing signals was set at $19.2 \mathrm{kHz}$, and the sampling point was set at 2048 points. In the following, the experimental steps and process of collecting data are illustrated.

(1) At normal work state of mill, the coal feeder was stopped, and during this operation only coal powder was output from the outlet and no coal was input from the inlet by coal feeder. This process lasted 10 minutes, and then there was no coal load $(0 \mathrm{t} / \mathrm{h})$ in the mill.

(2) Under the stable condition of $0 \mathrm{t} / \mathrm{h}$, the shell and the bearing vibration signals were collected simultaneously, and thirty pieces of data were collected at the forward and back bearing housing, separately.

(3) During the process of collecting bearings signals, four sensors installed on mill shell collected thirty pieces of data at angular positions $310^{\circ}, 320^{\circ}$, and $330^{\circ}$, separately.

(4) With the same method, the shell and bearing vibration signals were obtained under the $20 \mathrm{t} / \mathrm{h}, 30 \mathrm{t} / \mathrm{h}$, $35 \mathrm{t} / \mathrm{h}, 40 \mathrm{t} / \mathrm{h}, 45 \mathrm{t} / \mathrm{h}, 50 \mathrm{t} / \mathrm{h}$, and $55 \mathrm{t} / \mathrm{h}$ conditions, respectively. 
TABLE 3: The sensitivity index of reflecting the fill level change for different sensors.

\begin{tabular}{|c|c|c|c|c|c|c|}
\hline Adjacent conditions & Forward bearing (sensor 5) & Back bearing (sensor 6) & Sensor 1 & Sensor 2 & Sensor 3 & Sensor 4 \\
\hline $0 \mathrm{t} / \mathrm{h}, 20 \mathrm{t} / \mathrm{h}$ & 0.17535 & 0.38583 & 0.17277 & 0.075801 & 0.06955 & 0.034087 \\
\hline $20 \mathrm{t} / \mathrm{h}, 30 \mathrm{t} / \mathrm{h}$ & 0.54767 & 0.10914 & 0.17 & 0.2019 & 0.18071 & 0.15551 \\
\hline $30 \mathrm{t} / \mathrm{h}, 35 \mathrm{t} / \mathrm{h}$ & 0.082084 & 0.12782 & 0.10083 & 0.12498 & 0.12462 & 0.12549 \\
\hline $35 \mathrm{t} / \mathrm{h}, 40 \mathrm{t} / \mathrm{h}$ & 0.52685 & 0.09317 & 0.11314 & 0.11106 & 0.17316 & 0.18405 \\
\hline $40 \mathrm{t} / \mathrm{h}, 45 \mathrm{t} / \mathrm{h}$ & 0.13752 & 0.061331 & 0.30897 & 0.32467 & 0.25355 & 0.28187 \\
\hline $45 \mathrm{t} / \mathrm{h}, 50 \mathrm{t} / \mathrm{h}$ & 0.1194 & 0.67477 & 0.3774 & 0.4382 & 0.40363 & 0.43218 \\
\hline $50 \mathrm{t} / \mathrm{h}, 55 \mathrm{t} / \mathrm{h}$ & 0.096971 & 0.15895 & 0.52832 & 0.48956 & 0.54763 & 0.53186 \\
\hline Average & 0.24084 & 0.23014 & 0.25306 & 0.25231 & 0.25041 & 0.24929 \\
\hline
\end{tabular}

The RMS of forward and back bearing housing signals at every coal feed amount condition is the average value of RMS, which is obtained by

$$
X_{r m s}=\frac{1}{30} \sum_{i=1}^{30} \sqrt{\frac{1}{m} \sum_{n=1}^{m}\left(x_{n}^{i}\right)^{2}}
$$

where $m$ is the number of sampling point and is equal to 2048; $x_{n}^{i}(n=1,2, \ldots, 2048)$ is the discrete vibration value in time domain of $i$ th data.

In the process of calculating RMS of mill shell signals, the RMS is expressed by the average value of RMS of three angular position $\left(310^{\circ}, 320^{\circ}\right.$, and $\left.330^{\circ}\right)$ signals, which is expressed by

$$
\begin{aligned}
Y_{r m s}=\frac{1}{30} \sum_{i=1}^{30} \frac{1}{3}\left(\sqrt{\frac{1}{m} \sum_{n=1}^{m}\left(u_{n}^{i}\right)^{2}}\right. & \\
& \left.+\sqrt{\frac{1}{m} \sum_{n=1}^{m}\left(v_{n}^{i}\right)^{2}}+\sqrt{\frac{1}{m} \sum_{n=1}^{m}\left(w_{n}^{i}\right)^{2}}\right),
\end{aligned}
$$

where $m$ is the number of sampling point and is equal to 4096; $u_{n}^{i}(n=1,2, \ldots, 4096)$ is the discrete vibration value in time domain of $i$ th data collected at angular position $310^{\circ}$; $v_{n}^{i}(n=1,2, \ldots, 4096)$ is the discrete vibration value in time domain of $i$ th data collected at angular position $320^{\circ} ; w_{n}^{i}(n=$ $1,2, \ldots, 4096)$ is the discrete vibration value in time domain of $i$ th data collected at angular position $330^{\circ}$.

Because signals amplitudes have very big differences between mill shell and bearing housing, these two kinds of signals are carried out by the normalization method. This normalization method is expressed by

$$
x_{i}^{\prime}=0.1+\frac{x_{i}-x_{\min }}{x_{\max }-x_{\min }} \times 0.8
$$

where $x_{i}^{\prime}$ is the data that are obtained by the normalization processing, $x_{i}$ is the RMS, $x_{\max }$ is the maximum RMS value in every condition at every vibration station, and $x_{\min }$ is the minimum RMS value in every condition at every vibration station.
The sensitivity index of reflecting fill level change is obtained by RMS variety of the adjacent coal feeder amount conditions, which is calculated by

$$
a_{i}=1-\frac{x_{i+1}^{\prime}}{x_{i}^{\prime}},
$$

where $a_{i}$ is the sensitivity index of reflecting fill level change, $x_{i}^{\prime}$ is obtained by the normalization processing for the RMS of the previous condition, and $x_{i+1}^{\prime}$ is obtained by the normalization processing for the RMS of the latter condition.

6.2. Comparison between the Vibration Signals of Mill Shell and Bearing Housings. Table 3 shows the sensitivity index of reflecting fill level change at every vibration station.

It is clearly seen from Table 3 that the sensitivity index of mill shell signals is higher than that of bearing housings which indicates that the vibration signals of mill shell are sensitive to detect the small changes of fill level and can also measure the great changes of fill level. So the vibration signals of mill shell are the superior signals for measuring fill level. At the same time it can be seen from Table 3 that the sensitivity index of forward bearing housing is higher than that of back bearing housing, which has a good agreement with existing research conclusion [19].

\subsection{The Correlation between the Vibration of Mill Shell and Fill} Level. Figure 12 shows the variation in the RMS amplitude of vibration signals of mill shell with coal feed amount. And RMS amplitudes are calculated by (24). In all sensors it is found that RMS amplitude decreases as coal feed amount (fill level) increases. The higher the coal load in the mill is, the more impact energy of steel balls is absorbed by coal powder, and the lower impact energy reaches the mill shell to cause relatively small vibration, and vice versa. This conclusion has a good agreement with the result of theoretical analysis. It shows that vibration strength of mill shell can reflect accurately the information of fill level.

At the same time in Figure 12, when coal feed amount increases from $0 \mathrm{t} / \mathrm{h}$ ( $0 \%$ fill level), at the same coal feed amount condition, measure point (such as sensor 1, as shown in Figure 3) is more close to the inlet of mill; its RMS amplitude is lower. Measure point (such as sensor 4, as shown in Figure 3) is more close to the outlet of mill, and its RMS amplitude is higher. It means that amount of coal powder 


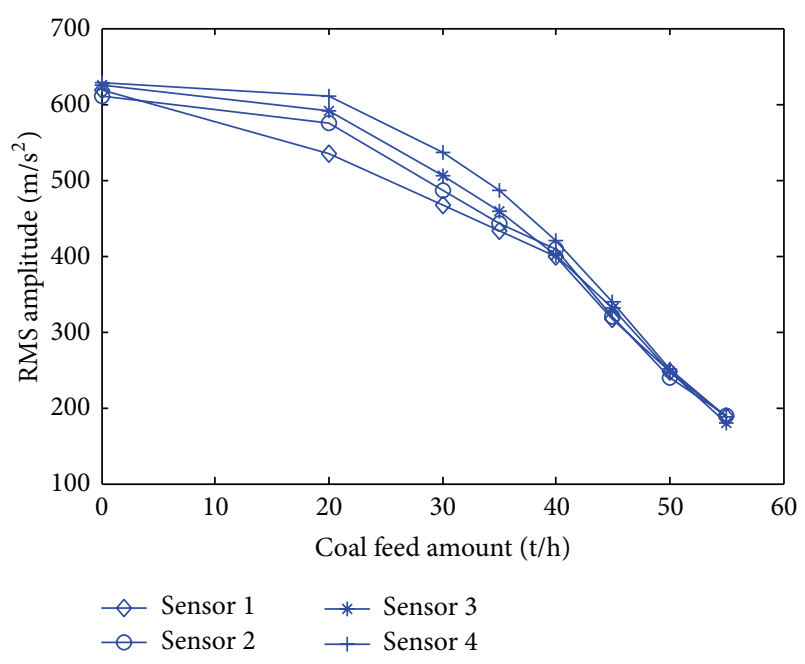

FIGURE 12: Variation in the RMS amplitude of vibration signals of mill shell with coal feed amount at various sensors.

near the inlet of mill is more, and amount of coal powder near the outlet of mill is little. This result is consistent with the distributional conclusion of coal powder in Section 2 (as shown is Figure 2(a)).

\section{Conclusions}

(1) The result that the nonuniform distribution of coal powder in roller is obtained by analyzing the axial and circumferential motion of coal powder, and the scheme that multiple acceleration sensors need to be installed on mill shell to acquire the information of fill level is confirmed.

(2) According to the characteristic of shell signals, a special data acquisition system was developed in this study to collect the vibration signals at different circumferential positions the mill shell.

(3) Based on impact model and hierarchical model of steel balls, the vibration frequency band of mill shell caused by impact of steel balls is obtained, which is combined with sampling theorem and actual data of mill shell to confirm the sampling frequency.

(4) Due to a close relationship existing in the vibration of mill shell and fill level, in this research the impact region of steel balls on mill shell was chosen as the region of data acquisition.

(5) The vibration signals of mill shell are compared with those of bearing housing according to the sensitivity of change of fill level, and this comparison reveals that the vibration signals of mill shell present higher sensitivity to changes on fill level. It indicates that the method of data acquisition proposed in this paper is valid.

(6) The relation between the vibration of mill shell and fill level shows that vibration strength of mill shell could well reflect the change of fill level, which provides a solid basis for the accurate measurement of fill level.

Because fill level of mill is a very important monitoring parameter and control variable for the optimal control of mill, optimal, automatic, and online control of ball mill system is studied based on fill level in author's research, which will be discussed in the next work.

\section{Conflict of Interests}

The authors declare that there is no conflict of interests regarding the publication of this paper.

\section{Acknowledgments}

The authors would like to thanks Professor Fei-yun $\mathrm{Xu}$ and Professor Jian-zhong $\mathrm{Hu}$ for the helpfulness of experiments. This work was funded under a Grant from the National Natural Science Foundation of China (no. 51005047).

\section{References}

[1] V. K. Gupta and S. Sharma, "Analysis of ball mill grinding operation using mill power specific kinetic parameters," Advanced Powder Technology, vol. 78-99, pp. 33-36, 2014.

[2] M. H. Wang, R. Y. Yang, and A. B. Yu, "DEM investigation of energy distribution and particle breakage in tumbling ball mills," Powder Technology, vol. 223, pp. 83-91, 2012.

[3] G. Si, H. Cao, Y. Zhang, and L. Jia, "Experimental investigation of load behaviour of an industrial scale tumbling mill using noise and vibration signature techniques," Minerals Engineering, vol. 22, no. 15, pp. 1289-1298, 2009.

[4] J. Tang, L. Zhao, J. Zhou, H. Yue, and T. Chai, "Experimental analysis of wet mill load based on vibration signals of laboratory-scale ball mill shell," Minerals Engineering, vol. 23, no. 9, pp. 720-730, 2010.

[5] Z.-G. Su, P.-H. Wang, and X.-J. Yu, "Immune genetic algorithmbased adaptive evidential model for estimating unmeasured parameter: estimating levels of coal powder filling in ball mill," Expert Systems with Applications, vol. 37, no. 7, pp. 5246-5258, 2010.

[6] K. Gugel and R. M. Moon, "Automated mill control using vibration signal processing," in Proceedings of the IEEE Cement Industry Technical Conference, pp. 17-25, Charleston, SC, USA, April 2007.

[7] K. Gugel, G. Palacios, J. Ramirez, and M. Parra, "Improving ball mill control with modern tools based on digital signal processing (DSP) technology," in Proceedings of the IEEEIAS/PCA 2003 Cement Industry Technical Conference, pp. 311318, Dallas, Tex, USA, May 2003.

[8] W. Heng and J. Minping, "A fuzzy control method for ball mill system based on fill level soft sensor," in Proceedings of the Chinese Control and Decision Conference (CCDC '09), pp. 58885891, Guilin, China, June 2009.

[9] Z.-G. Su, X.-J. Yu, and Z.-Z. Lv, "Judgment of ball-mills maximal coal pulverizing capacity based on gray incidence analysis of shaft vibration," Themal Power Generationr, no. 11, pp. 29-33, 2006.

[10] A. V. Oppenheim and A. S. Willsky, Signals and Systems, Prentice Hall, New York, NY, USA, 2000. 
[11] C.-T. Chen, Digital Signal Processing Spectral Computation and Filter Design, Oxford University Press, Oxford, UK, 2001.

[12] J. Chen, The Technique of Noise Control for the Ball Mill, China Power Press, Beijing, China, 2002.

[13] B.-L. Zhong and R. Huang, Introduction to Machine Fault Diagnosis, China Machine Press, Beijing, China, 2007.

[14] S.-Y. Zhou, L. Yi, and J.-S. Li, "Analysis on fatigue of ball mill based on finite element method," Mining Processing Equipment, vol. 41, no. 1, pp. 60-63, 2013.

[15] L.-T. Chen, Y.-J. Xue, and Y. Liu, "Modal analysis of oversize ball mill tube based on ANSYS," Advanced Material Research, vol. 889-890, pp. 62-65, 2014.

[16] X.-Y. J, Q.-K. Sun, and L.-J. Yin, "Application of equipment condition monitoring and fault diagnosis," Machine Tool \& Hydraulics, vol. 39, no. 22, pp. 129-131, 2011.

[17] P. Huang, M.-P. Jia, and B.-L. Zhong, "New method to measure the fill level of the ball mill I-Theoretical analysis and DEM simulation," Chinese Journal of Mechanical Engineering, vol. 23, no. 4, pp. 460-467, 2010.

[18] P. Huang, M.-P. Jia, and B.-L. Zhong, "Analysis of the relation between charge motion and fill level of the ball mill using the DEM simulation," in Proceedings of the International Conference on Information Science and Engineering, pp. 1647-1650, Yangzhou, China, September 2011.

[19] H. Wang, M. Jia, and Z. Chen, "Fill-level measuring and control system based on multi-sensor information fusion for ball mill," Electric Power Automation Equipment, vol. 32, no. 9, pp. 138-141, 2012. 


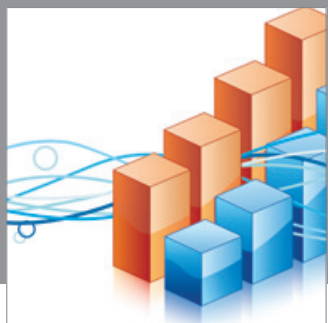

Advances in

Operations Research

mansans

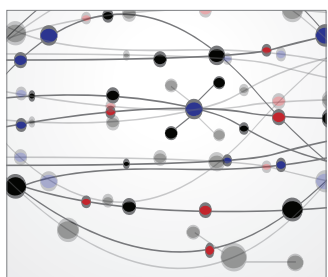

The Scientific World Journal
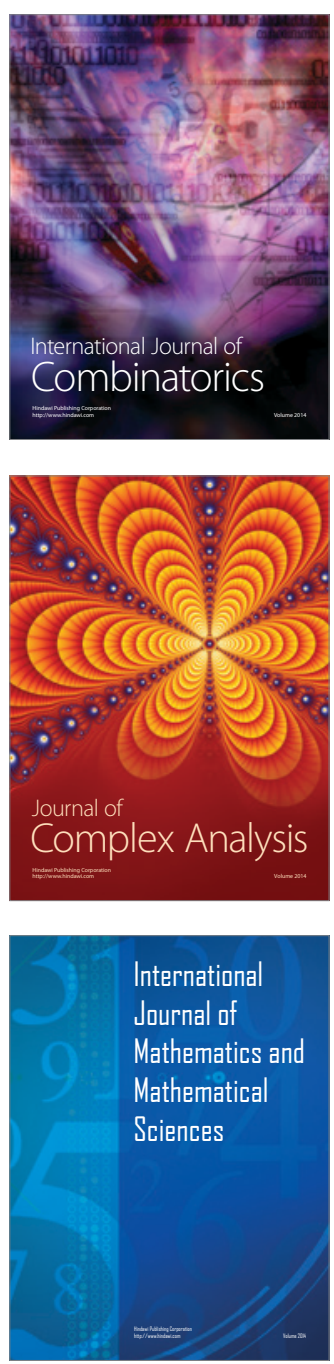
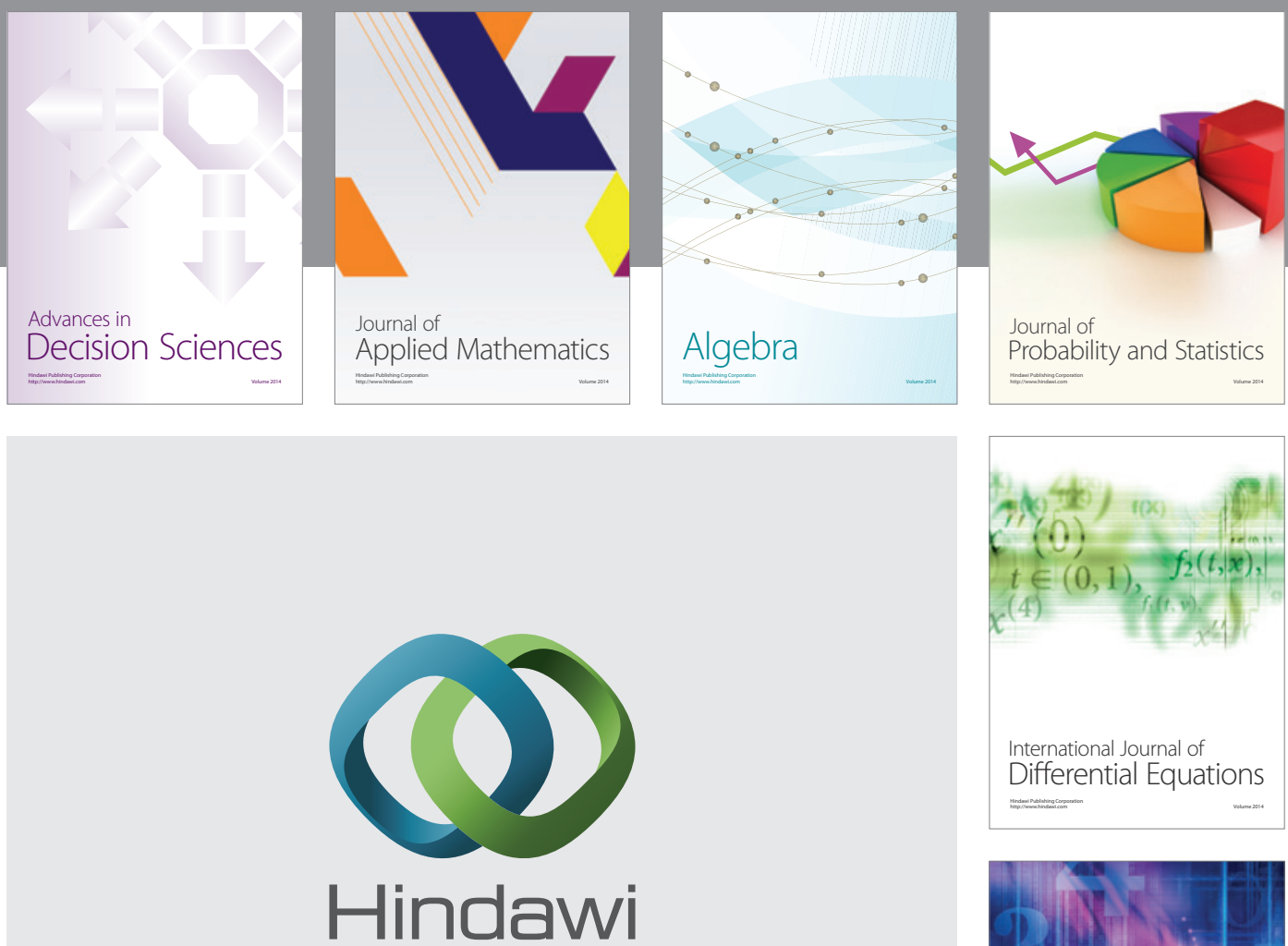

Submit your manuscripts at http://www.hindawi.com
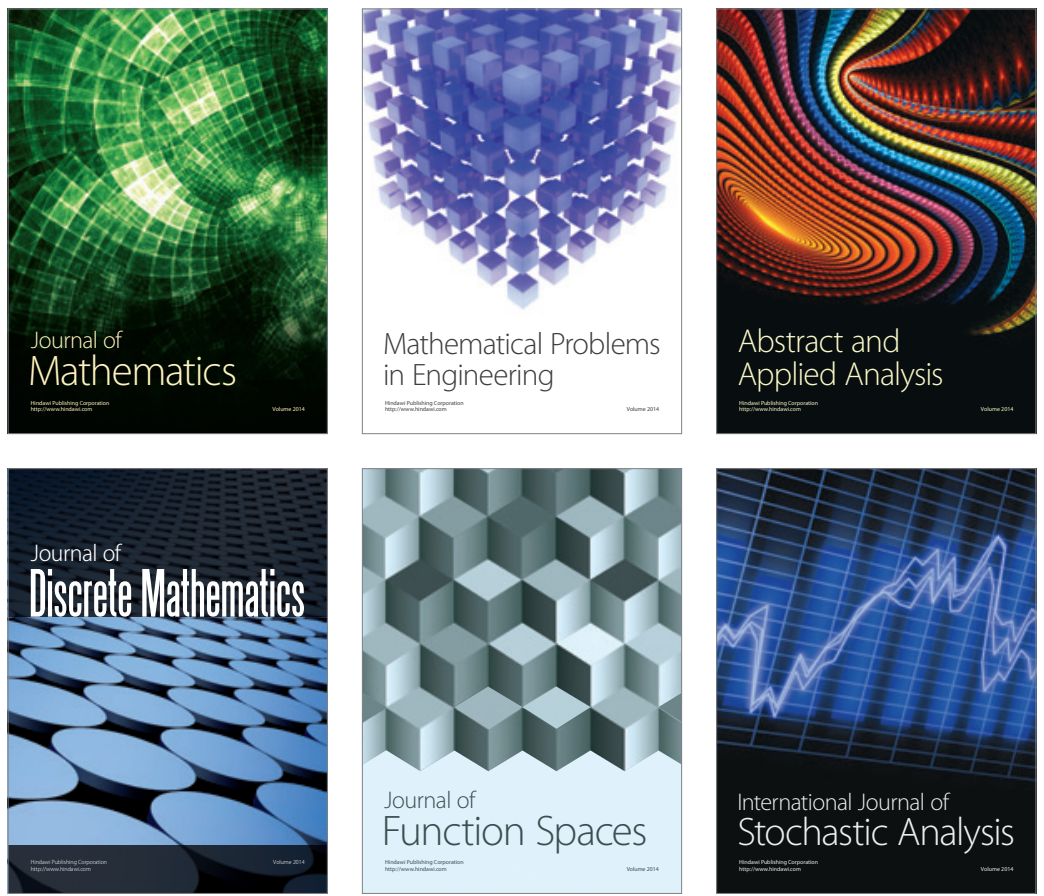

Journal of

Function Spaces

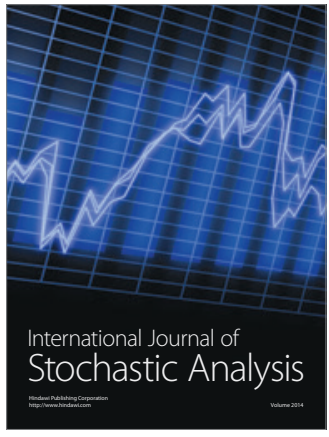

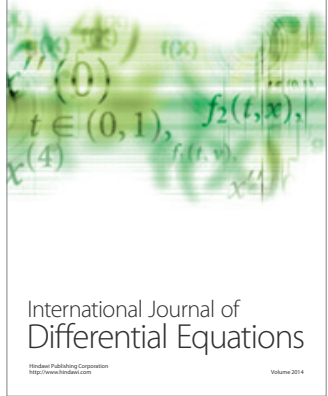
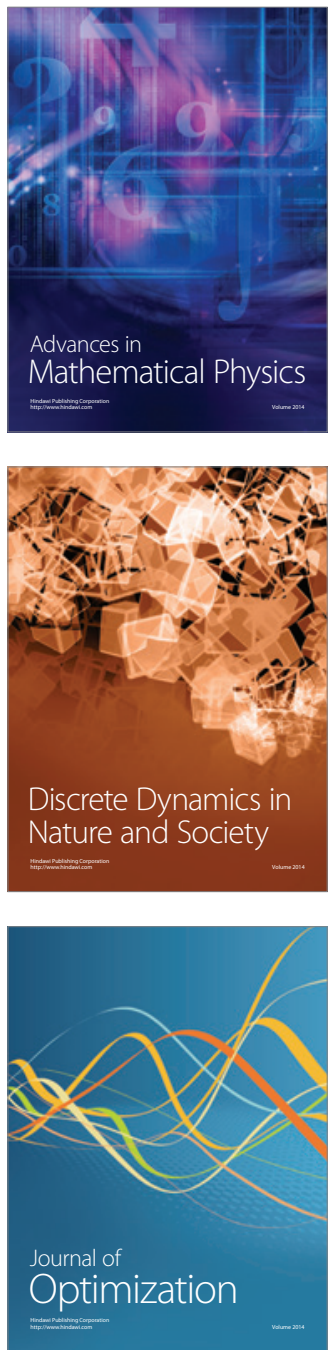